\title{
Treatment of Acute Massive Pulmonary Embolism by Streptokinase during Labour and Delivery
}

\author{
R. J. C. HALL, C. YOUNG, G. C. SUTTON, S. CAMBELL
}

British Medical fournal, 1972, 4, 647-649

\section{Summary}

A 29-year-old woman sustained an acute massive pulmonary embolism in the 32nd week of pregnancy. Rapid clinical improvement followed the use of streptokinase. Treatment was continued for 41 hours, including labour and the first three hours after delivery. There was slow but severe postpartum haemorrhage. Partial uterine atony occurred, and may have been due, at least in part, to fibrin degradation products arising from thrombolysis. No adverse effects were noted in the baby.

Our experience suggests that streptokinase may be given during labour but that an oxytocic agent may be needed; and that reversal of fibrinolysis before delivery is best achieved by the use of aprotinin (Trasylol) rather than aminocaproic acid.

\section{Introduction}

Thrombolytic therapy has been used in the last two decades to treat a variety of thrombotic and thromboembolic conditions. Renewed interest in thrombolytic therapy has resulted from the development of thrombolytic agents of greater purity. One such agent, streptokinase, usually produces rapid resolution of pulmonary embolism (Hirsh et al., 1968; Miller et al., 1969). Such resolution assessed by pulmonary arteriography is significantly greater after treatment with streptokinase than with heparin over a 72-hour period as shown by pulmonary arteriography (Miller et al., 1971). Pregnancy and recent surgery may both predispose to venous thrombosis and pulmonary embolism, and indeed thromboembolism is now the second most common cause of maternal mortality (Department of Health and Social Security, 1969). A fatal thromboembolic episode occurs once in every 25,000 pregnancies (Ministry of Health, 1969) and, although the incidence of non-fatal thromboembolism is less easily established, a figure of 3.3 per thousand pregnancies has been reported (Jeffcoate and Tindall, 1965).

A case of massive pulmonary embolism occurring during pregnancy and treated with streptokinase is reported. The management is discussed with particular reference to the complications of thrombolytic therapy.

\section{Case History}

A 29-year-old woman was admitted to hospital in the 32nd week of her second pregnancy for excision of a suspected malignant melanoma on her left calf. The next day the lesion was widely excised and skin-grafting was performed. Histological examination of the lesion showed it to be a benign lentigo. She was confined to bed for six days postoperatively. On the eighth post-

Cardiac Department, Brompton Hospital, London S.W.3

R. J. C. HALL, M.B., M.R.C.P., Senior House Officer

Consultant Physician, Hillingdon Hospital, Nr. Uxbridge, Middlesex.)

Chelsea Hospital for Women, London S.W.3

C. YOUNG, M.R.C.S., M.R.c.o.G., Resident Surgical Officer

Institute of Obstetrics and Gynaecology, Queen Charlotte's

Hospital, London W.6

S. CAMPBELL, M.B., M.R.C.o.G., Senior Lecturer

operative day she suddenly became dizzy, severely breathless, and had mild central chest pain while walking in the ward. Pulmonary embolism was diagnosed and anticoagulation was begun with intravenous heparin. Nine hours later her condition deteriorated, she became centrally cyanosed, hypotensive, and the extremities were cold. Morphine was given before transfer to the Brompton Hospital. Occasional uterine contractions had occurred before the journey, but these diminished. Twelve hours after the onset of symptoms the patient was drowsy and centrally cyanosed but the extremities were warm. The blood pressure was $105 / 80 \mathrm{~mm}$ $\mathrm{Hg}$, she was tachypnoeic (respiratory rate $30 / \mathrm{min}$ ) with a sinus tachycardia of 140 , and a small sharp pulse. The jugular venous pressure was raised $10 \mathrm{~cm}$ above the sternal edge. The plain chest radiograph was normal, and the E.C.G. showed sinus tachycardia (rate 150), and an S1-Q3-T3 pattern, and an rSr pattern in lead VI.

Analysis of arterial blood showed $\mathrm{pO}_{2} 41 \mathrm{~mm} \mathrm{Hg}, \mathrm{pCO}_{2}$ $30 \mathrm{~mm} \mathrm{Hg}$, and $\mathrm{O}_{2}$ saturation $76 \%$. The $\mathrm{pH}$ was 7.45 . There was no clinical or ultrasonic evidence (Evans and Cockett, 1969) of deep vein thrombosis in either leg. Right heart catheterization showed: Right atrium $a=17, x=16, v=17, y=16 \mathrm{~mm} \mathrm{Hg}$ (mean =17); right ventricle $35 / 13-18 \mathrm{~mm} \mathrm{Hg}$; and pulmonary artery $34 / 23 \mathrm{~mm} \mathrm{Hg}($ mean $=27)$. Total pulmonary resistance was 13 units $/ \mathrm{m}^{2}$. Cardiac index was $2 \cdot 11 . / \mathrm{min} / \mathrm{m}^{2}$.

Pulmonary arteriography, while confirming the diagnosis of massive pulmonary embolism, showed an unusual appearance in that there was a saddle embolus at the bifurcation of the main pulmonary artery with good filling of peripheral vessels by the contrast medium (see figure).

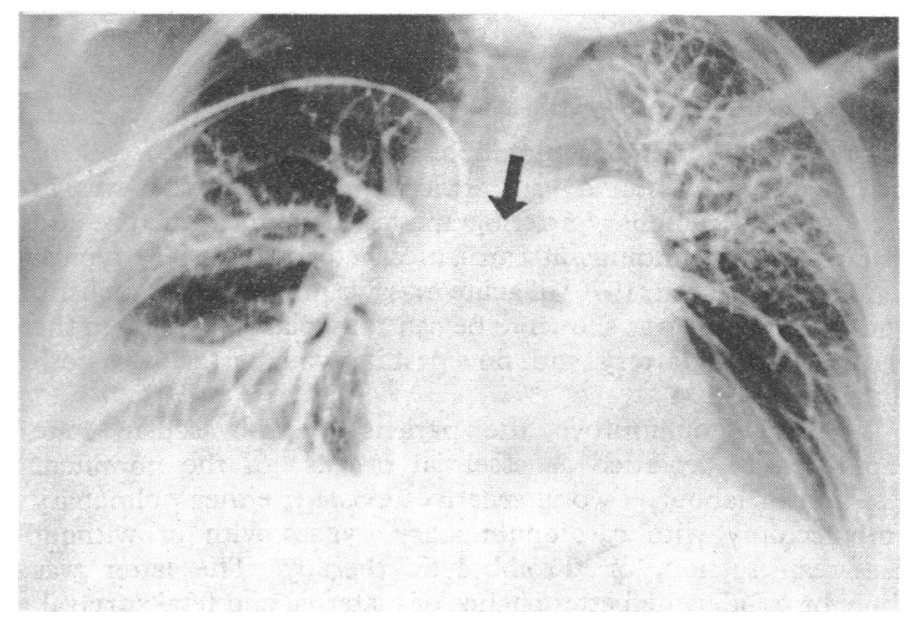

Pulmonary arteriogram showing centrally placed embolus extending into right pulmonary artery.

PROGRESS

After pulmonary arteriography labour began. Abdominal palpation showed a good sized baby possibly compatible with a gestation period of more than 32 weeks. On vaginal examination the cervix was not effaced and dilated $2 \mathrm{~cm}$. She was treated with 600,000 units of streptokinase in $100 \mathrm{ml} 5 \%$ dextrose infused into a peripheral vein over half an hour and continued with 100,000 units hourly (Miller et al., 1969). Hydrocortisone $100 \mathrm{mg}$ six-hourly was given intravenously to avoid febrile reactions to streptokinase.

Eight hours later the patient was greatly improved. She was no longer dyspnoeic, the venous pressure was lower, and the heart rate was slower. She was now having contractions every two to three minutes, and vaginal examination showed the cervix 
to be effaced and 4-cm dilated. Although some clear liquor was draining the forewaters were thought to be intact, and were ruptured. The liquor obtained was clear, and the fetal heart rate was $170 / \mathrm{min}$ at this time. Ten hours after starting treatment the contractions were uncomfortable, and $50 \mathrm{mg}$ pethidine were given by intramuscular injection. The contractions then diminished and had stopped 12 hours after starting treatment with streptokinase. Throughout the rest of the labour the fetal heart remained regular at a rate of between 140 and $160 / \mathrm{min}$.

Twenty-nine hours after starting streptokinase intravenous infusion of oxytocin was begun, and given in incremental dosage. After three hours labour was re-established. By this time the patient's venous pressure had fallen to $0 \mathrm{~cm}$ of saline and the pulse rate to $100 / \mathrm{min}$. Throughout the rest of labour her cardiovascular state remained stable. The haemoglobin was $11.2 \mathrm{~g} / 100 \mathrm{ml}$, and as haemorrhage at delivery was expected two pints $(1 \cdot 11$.$) of$ whole blood were given. At 37 hours vaginal examination showed the cervix to be fully effaced and $8-\mathrm{cm}$ dilated. An hour later the fetel vertex was visible, and she had a spontaneous vaginal delivery without episiotomy. Ergometrine $0.5 \mathrm{mg}$ was given intravenously, and the placenta was delivered by controlled cord traction. The measured blood loss was $350 \mathrm{ml}$. The infant, a healthy female, weighed $2,400 \mathrm{~g}$, and cried spontaneously. No external evidence of any bleeding tendency was found. After the third stage slow but persistent uterine haemorrhage occurred despite intravenous infusion of 0.4 units of oxytocin per minute and intermittent fundal massage. Streptokinase was therefore stopped after a total treatment period of 41 hours. Vaginal bleeding continued, however, and two hours later $8 \mathrm{~g}$ of aminocaproic acid were given to reverse fibrinolysis, and fundal massage was performed continuously. These measures produced haemostasis. Eleven bottles of blood had been transfused during the first six hours postpartum. The infusion of oxytocin was continued for 36 hours after delivery, and $0.5 \mathrm{mg}$ ergometrine was given three times daily by mouth for five days. Oestrogens were not used to suppress lactation (Jeffocoate and Tindall, 1965).

The patient's subsequent medical and obstetric course was uneventful, and anticoagulation with warfarin was begun soon after delivery.

\section{Discussion}

Acute massive pulmonary embolism during the 32nd week of pregnancy had resulted in a critically ill patient who was in labour after pulmonary arteriography. The clinical picture and haemodynamic findings at cardiac catheterization were typical (Miller and Sutton, 1970) of acute massive pulmonary embolism, and the embolus was shown to be centrally placed, mainly in the right pulmonary artery, with flow past it giving perfusion of both lungs.

Measures to improve the patient's cardiovascular state rapidly were regarded as essential because of the imminent exertion of labour. Two alternatives existed; either pulmonary embolectomy with cardiopulmonary bypass with or without caesarean section, or thrombolytic therapy. The latter was thought to offer the better chance of maternal and fetal survival, although it has been thought by others that saddle pulmonary embolism is a firm indication for immediate pulmonary embolectomy (Hirsh et al., 1968).

Thrombolytic therapy with comparable doses of streptokinase given during pregnancy has been reported by Ludwig (22 cases) and Pfeiffer (15 cases) (Ludwig, 1968; Pfeiffer, 1970). All their patients had major thromboses in the femoral or iliac veins, but only two had pulmonary emboli. In neither of these series, which included women at all stages of pregnancy, was there any evidence of subsequent antepartum haemorrhage or damage to the fetus. The use of thrombolytic therapy during labour and the early puerperium has not been previously described.

Animal experiments (Ludwig, 1966) with unlabelled streptokinase show that depending on the species between 0.1 and $1 \%$ of doses in the therapeutic range cross the placenta.

In the case described here there was no external evidence of haemorrhage in the baby at birth. The baby had a euglobulin lysis time of $9.5 \mathrm{~min}$ (normal range in cord blood 10-330 $\mathrm{min}$.
(Ekelund et al., 1970)), normal fibrinogen levels, and a slightly prolonged prothrombin time. The placental histology was normal. These data suggest that after $\mathbf{4 0}$ hours of treatment with streptokinase the fetus was not adversely affected.

The greatest problem was a slow but persistent postpartum haemorrhage. This was associated with failure of the uterus to remain firmly contracted despite large doses of oxytocic agents. Haemostasis at the placental site is generally thought to be mechanical, and women with severe thrombocytopenia or receiving anticoagulant treatment may be delivered without excessive blood loss providing uterine atony does not occur (Basu, 1969). During thrombolysis fibrin is broken down into a series of degradation products which are released into the circulation. These may cause a variety of haemostatic defects which cannot be reversed by anti-fibrinolytic agents such as aminocaproic acid or aprotinin. Fibrin degradation products have been shown to inhibit myometrial contractility in vitro. This may be due both to interference with ionic transport across the myometrial cell membrane (Malofiewjew et al., 1971) and local inhibition of kininases (Hamberg, 1969). The latter are responsible for the breakdown of pharmacologically active amines such as bradykinin, and if these are allowed to accumulate locally they may inhibit uterine contraction (Landesman et al., 1963).

In the present patient the levels of fibrin degradation products were assayed only at delivery, when they were at the upper limit of normal $(0.96 \mu \mathrm{g} / \mathrm{ml})$. It is possible that they were higher at other times during treatment and may have been responsible, at least in part, for the discontinuance of established labour 12 hours after the onset of streptokinase therapy, and also for the uterine atony which occurred postpartum. The reason for rupturing the membranes and expediting delivery once this appeared inevitable was the fear of placental separation during labour. If the inhibitory effects of either plasmin acting as a possible oxytocinase or fibrin degradation products as described above had been expected we might not have interfered. The postpartum haemorrhage was controlled by stopping treatment with streptokinase, administering aminocaproic acid to reverse fibrinolysis, and using continuous fundal massage to maintain uterine contraction after large doses of oxytocic agents alone had failed. Stopping of the haemorrhage may have resulted from any of these measures, but we regard the fundal massage as important.

Aminocaproic acid was used here to reverse fibrinolysis five hours after delivery. It is a small molecule readily crossing the placental barrier, and should not therefore be used during pregnancy when aprotinin (Trasylol), which has a larger molecule and does not readily cross the placenta, is to be preferred (Pfeiffer, 1970). In addition, a correlation has been found in premature babies between low levels of endogenous fibrinolytic activity and the occurrence of the respiratory distress syndrome (Makarin et al., 1967). The use of aminocaproic acid near term might therefore, at least theoretically, predispose to this syndrome in the infant.

As a result of our experience with the present patient, certain factors relating to the use of streptokinase in pregnancy and particularly during labour have emerged: (1) labour continues satisfactorily during treatment with streptokinase if oxytocic agents are used; (2) in order to prevent serious postpartum haemorrhage consideration should be given to stopping streptokinase four to six hours (which is the half life of fibrin degradation products) before delivery is expected; (3) continuous massage of the fundus, postpartum, is recommended to prevent uterine relaxation; and (4) if reversal of fibrinolysis is required before delivery, aprotinin rather than aminocaproic acid should be used.

We would like to thank Dr. R. V. Gibson for his help and advice, and for permission to report this case, which was under his care.

Requests for reprints should be addressed to: Dr. G. C. Sutton, Hillingdon Hospital, Nr. Uxbridge, Middlesex. 


\section{References}

Basu, H. K. (1969). Fournal of Obstetrics and Gynaecology of the British Commonwealth, 76, 481.

Ekelund, H., Hedner, U., and Nilsson, I. M. (1970). Acta Paediatrica Scandinavica, 59, 33.

Evans, D. S., and Cockett, F. B. (1969). British Medical fournal, 2, 802

Hamberg, U. (1969). Proceedings of the Royal Society of Medicine, Series B, $173,393$.

Hirsh, J., Hale, G. S., McDonald, I. G., McCarthy, R. A., and Pitt, A. (1968). British Medical fournal, 4, 729.

Jeffcoate, T. N. A., and Tindall, V. R. (1965). Australia and New Zealand Fournal of Obstetrics and Gynaecology, 5, 119

Landesman, R., Campbell, W. L., and Wilson, K. H. (1963). Obstetrics and Gynaecology, 22, 102.
Ludwig, H. (1966). Geburtshilfe und Frauenheilkunde, 26, 736.

Ludwig, H. (1968). Gynaecologia, 166, 20.

Makarian, M., Githens, J. H., and Jackson, J. J. (1967). American fournal of Diseases of Children, 113, 312

Malofiewjew, M., Kostrzewska, A., and Buluk, K. (1971). Experientia, 27, 139.

Miller, G. A. H., Gibson, R. V., Honey, M., and Sutton, G. C. (1969). British Medical fournal, 1,812 Miller, G. A. H., and Sutton, G. C. (1970). British Heart fournal, 32, 158. (1971) British Medical fournal, 2, 681 .

Department of Health and Social Security (1969). Report on Confidential Enquiries into Maternal Deaths in England and Wales 1964-1966. London, H.M.S.O.

Pfeiffer, G. W. (1970). Australian Annals of Medicine, 19, Suppl. p. 17, 28.

\section{MEDICAL MEMORANDA}

\section{Paroxysmal Nocturnal Haemoglobinuria-like Red Cell Abnormality in Patient with Lymphoproliferative Disease}

\section{R. S. HILL, D. CATOVSKY, S. M. LEWIS}

\section{British Medical fournal, 1972, 4, 649-650}

Paroxysmal nocturnal haemoglobinuria is diagnosed on the basis of a positive acidified serum lysis test. An association between the disease and aplastic anaemia is well established (Lewis and Dacie, 1967). The development of a paroxysmal nocturnal haemoglobinuria-like abnormality-that is, a positive acidified serum lysis test-has been seen in myelosclerosis (Lewis et al., 1971) and, conversely, acute myeloblastic leukaemia has developed in at least six patients with pre-existing paroxysmal nocturnal haemoglobinuria. The patient reported here developed a positive acidified serum test during the course of a lymphoproliferative malignant disease. He had a concomitant autoimmune haemolytic anaemia and hypogammaglobulinaemia.

\section{Case Report}

A caucasian man, aged 59 years was admitted to Hammersmith Hospital in April 1969 with a six-week history of lymph node enlargement, sweating, and weight loss. On clinical examination he was apyrexial, not jaundiced, and had no petechiae or bruising. Large $(2-4 \mathrm{~cm})$ very firm anterior and posterior cervical nodes, and palpable auricular, submandibular, and submental nodes were present. There was a $20-\mathrm{cm}$ splenomegaly and $6-\mathrm{cm}$ hepatomegaly. Occasional haemorrhages were present in both fundi. The blood count gave the following results: haemoglobin $8.4 \mathrm{~g} / 100 \mathrm{ml}$, reticulocytes $0.8 \%$, platelets $107,000 / \mathrm{mm}^{3}$, W.B.C. $370,000 / \mathrm{mm}^{3}$ with $82 \%$ lymphocytes. The lymphocytes were predominantly small mature cells, but about $15 \%$ were larger nucleolated lymphoid cells showing varying degrees of immaturity. A direct antiglobulin test was strongly positive (IgG). The bone marrow was markedly hypercellular and infiltrated with predominantly small mature lymphocytes. Larger nucleolated lymphoid cells were present in

M.R.C. Leukaemia Unit and Department of Haematology, Royal Postgraduate Medical School, London W.12

CATOVSKY, D., M.D., Assistant Lecturer in Haematolog HILL, R. S., M.R.A.C.P., Commonwealth Research Fellow LEWIS, S. M. M.D., M.R.C.PATH., Reader in Haematology numbers comparable to those found in the peripheral blood. Uric acid was $9.1 \mathrm{mg} / \mathrm{ml}$, bilirubin $0.4 \mathrm{mg} / 100 \mathrm{ml}$, alkaline phosphatase 19 K.A. units, serum albumin was $3.5 \mathrm{~g} / 100 \mathrm{ml}$, and globulin was $2 \cdot 1 \mathrm{~g} / 100 \mathrm{ml}$. Immunoglobulins were: IgG 820, $\operatorname{IgA} 85$, and $\operatorname{IgM}$ less than $10 \mathrm{mg} / 100 \mathrm{ml}$. No serum myeloma-like protein was present. However, Bence Jones protein, type $k$, was detected in a concentration of $4 \mathrm{mg} / 100 \mathrm{ml}$. A ${ }^{51} \mathrm{Cr}$ red cell survival study was normal ( $\mathrm{T}_{50} 24$ days). A chest $x$-ray film showed bilateral hilar lymphadenopathy, confirmed by tomography. A diagnosis of chronic lymphocytic leukemia was made, although the atypical blood and bone marrow morphology and strikingly firm lymphadenopathy on palpation raised the possibility of this being a variant of lymphocytic lymphoma.

The patient was treated with chlorambucil, $5 \mathrm{mg} /$ day, allopurinol $400 \mathrm{mg} /$ day, and prednisone $40 \mathrm{mg} /$ day. He was discharged 16 days after admission on prednisone $40 \mathrm{mg} /$ day and allopurinol $300 \mathrm{mg} /$ day. He was then symptom-free and the lymphadenopathy was greatly reduced. The evolution of the disease is shown in the chart.

Between May and August 1969 he became progressively anaemic with increasing anorexia, fever, and sweats, despite receiving chlorambucil and prednisone. He was readmitted to hospital in August. Examination showed splenomegaly $(6 \mathrm{~cm})$, hepatomegaly $(7 \mathrm{~cm})$, and multiple very firm axillary, cervical, and inguinal nodes. Haemoglobin was $5.8 \mathrm{~g} / 100 \mathrm{ml}$, reticulocytes were $22 \%$, platelets were $88,000 / \mathrm{mm}^{3}$, and W.B.C. was $9,000 / \mathrm{mm}^{3}$ with $87 \%$ lymphocytes. The peripheral blood film showed spherocytes, polychromasia, and anisocytosis. A direct antiglobulin test was again strongly positive (IgG). In an auto-red cell survival study the ${ }^{51} \mathrm{Cr} \mathrm{T}_{50}$ was eight days, and surface counting showed that the spleen was the principal site of red cell destruction. As the acute haemolysis did not respond to high doses of prednisone, splenectomy was performed. The spleen weighed $980 \mathrm{~g}$; its sinuses were packed with red cells and widened splenic cords contained many lymphocytes, some mature and some poorly differentiated. Sections of a superficial lymph node removed at the time of surgery showed that the normal cellular architecture had been completely replaced by a uniform mass of rather poorly differentiated lymphocytes. Splenectomy was followed by a rapid improvement in the blood count. and the patient was discharged in October on prednisone, $5 \mathrm{mg} /$ day (see chart). Haemoglobin was $11.5 \mathrm{~g} / 100 \mathrm{ml}$, reticulocytes were $1.8 \%$, W.B.C. was $16,000 / \mathrm{mm}^{3}$, and platelets were $454,000 / \mathrm{mm}^{3}$. A red cell survival study performed one month later was normal ( $T_{50} 25$ days).

From February to June 1971 superficial lymph nodes showed progressive enlargement despite continuing chemotherapy. In June of that year a five-week course of local radiotherapy was given to enlarging cervical and inguinal nodes, with subsequent shrinkage of the tumour masses. In August an inguinal node was also irradiated. From then until November the patient showed continuing clinical deterioration without evidence of further superficial node enlargement.

On his final admission in November he was sick, wasted, and pyrexial. The superficial nodes were not enlarged above $1.5 \mathrm{~cm}$. A lymphangiogram, however, showed the presence of large abnormal para-aortic glands, and a chest radiograph showed the recurrence of bilateral hilar lymphadenopathy. Accordingly he was started on a course of radiotherapy to the para-aortic region (see 